\title{
Based on the MADM model wine sales manager competency research
}

\author{
Lingxiao $\mathrm{Lv}^{1}$, Jing Zeng ${ }^{2}$ \\ ${ }^{1}$ School of Economics and Management, Harbin Institute of Technology, Weihai, Shandong, 264200, China; \\ ${ }^{2}$ School of Food and Wine, Ningxia University, Yinchuan, Ningxia, 750000, China.
}

\begin{abstract}
In order to solve the problem of the lack of professional wine marketing team, this paper identified the key influencing factors of wine sales managers from the competency point of view, constructed the competency model and evaluation index system of wine sales managers, and introduced the improved multiattribute decision making method (MADM) to evaluate the competency. The results show that there is an interactive relationship between the competency dimensions and indicators of wine sales managers, and the professional knowledge dimension has the greatest influence on the other four dimensions. Based on these findings, suggestions are made for future research.
\end{abstract}

\section{Introduction}

In recent years, with the improvement of people's consumption level and the gradual formation of the concept of health and health, wine has begun to enter the attention of consumers with its characteristics of beneficial cardiovascular, beauty and skin care. Although statistics predict that China will become the world's second largest wine consumer in 2022, wine only accounts for $1.5 \%$ of the total annual wine consumption in terms of the consumption structure of domestic beverage wine, so there is considerable space for the development of China's wine market. Therefore, with the rapid development of the market, the wine industry needs complex professionals with global thinking.

\section{Determine Competency Characteristics}

Follow the principle of science, this study on the literature review, discussion, and experienced experts in wine sales manager has carried on the thorough analysis, identifies 5 dimensions, respectively Personal traits(A),Marketing management ability (B), Professional knowledge (C), Selfmanagement ability (D) and Physical quality (E). The key factors that influence wine sales managers are showed in Table 1.

\section{Methods}

Multiple Attribute Decision Making (MADM) refers to the Decision problem of choosing the optimal solution or ranking the solution under the condition of considering Multiple attributes, which mainly adopts DEMATEL technology and DANP (DEMATEL-BASD Analytic Network Process).

Table 1 The key factors that influence wine sales managers

\begin{tabular}{|c|c|}
\hline Dimensions/Criteria & Contents \\
\hline Personal traits (A) & Work attitude and values \\
\hline Team spirit (a1) & Sense of teamwork \\
\hline Adaptive (a2) & $\begin{array}{l}\text { The ability to adapt to the } \\
\text { new environment }\end{array}$ \\
\hline $\begin{array}{l}\text { Marketing management } \\
\text { ability (B) }\end{array}$ & Flexible marketing strategy \\
\hline Policy sensitivity（b1） & $\begin{array}{l}\text { Information processing } \\
\text { ability of market policy }\end{array}$ \\
\hline $\begin{array}{l}\text { Customer Service } \\
\text { Awareness (b2) }\end{array}$ & Satisfy the customer's wishes \\
\hline $\begin{array}{l}\text { Professional knowledge } \\
\text { (C) }\end{array}$ & $\begin{array}{l}\text { Marketing related education } \\
\text { and experience }\end{array}$ \\
\hline Wine knowledge (c1) & $\begin{array}{l}\text { Wine professional technical } \\
\text { ability }\end{array}$ \\
\hline Experience $(\mathrm{c} 2)$ & Experience in wine industry \\
\hline $\begin{array}{l}\text { Self-management ability } \\
\text { (D) }\end{array}$ & $\begin{array}{l}\text { Thinking and behavior are } \\
\text { constantly improved }\end{array}$ \\
\hline Learning ability (d1) & $\begin{array}{l}\text { Ability to learn new } \\
\text { knowledge }\end{array}$ \\
\hline Innovation ability $(\mathrm{d} 2)$ & $\begin{array}{l}\text { Ability to adapt to the new } \\
\text { technology }\end{array}$ \\
\hline Physical quality (E) & Physical health \\
\hline Mental state (e1) & Mental stability \\
\hline Compressive ability（e2） & $\begin{array}{c}\text { Acceptability to work under } \\
\text { high intensity }\end{array}$ \\
\hline
\end{tabular}

\subsection{Based on DEMATEL technique to identify interaction relations}

DEMATEL technique is put forward by the research centre for the first time from Geneva, the main purpose is to solve the impact between the complex relationship

\footnotetext{
*Corresponding author: 19s030220@stu.hit.edu.cn
} 
between the network, through the establishment of relationship between network diagram (influence network relation map, INRM) to explore the interaction relationship between the various indicators. Therefore, this paper analyses the interaction relationship between key competency indicators based on the DEMATEL technique. The specific steps are as follows.

Step 1: Obtain the initial score matrix $\boldsymbol{A}$
A total of 7 wine experts were asked to rate the degree to which each of 10 key competency traits influenced the other. After several rounds of modification, until experts no longer modify their opinions, the initial score matrix $A$ is finally obtained, which is constituted by the degree of mutual influence among key competency characteristics. The initial influence matrix $\boldsymbol{A}$ is showed in Table 2 .

Table 2 The initial influence matrix $\boldsymbol{A}$

\begin{tabular}{cccccc}
\hline matrix $\boldsymbol{A}$ & $\mathrm{a} 1$ & $\mathrm{a} 2$ & $\mathrm{~b} 1$ & $\mathrm{~b} 2$ & $\mathrm{c} 1$ \\
\hline $\mathrm{a} 1$ & 0 & 2.4096 & 3.3334 & 3.3479 & 2.2614 \\
$\mathrm{a} 2$ & 3.7187 & 0 & 2.2941 & 2.1868 & 2.1376 \\
$\mathrm{~b} 1$ & 2.7748 & 3.6021 & 0 & 2.7362 & 2.9039 \\
$\mathrm{~b} 2$ & 2.2301 & 2.1217 & 2.5816 & 0 & 2.154 \\
$\mathrm{c} 1$ & 3.2811 & 2.6221 & 2.1016 & 3.8844 & 0 \\
$\mathrm{c} 2$ & 3.7301 & 3.8283 & 2.2637 & 3.0123 & 3.0842 \\
$\mathrm{~d} 1$ & 2.8801 & 2.6999 & 3.6733 & 2.9759 & 3.6285 \\
$\mathrm{~d} 2$ & 2.2941 & 3.5814 & 2.9051 & 2.9811 & 2.4705 \\
$\mathrm{e} 1$ & 2.4977 & 3.9394 & 2.3664 & 2.4199 & 3.0229 \\
$\mathrm{e} 2$ & 2.2604 & 2.8748 & 3.7603 & 3.5817 & 3.4282 \\
\hline matrix $\boldsymbol{A}$ & $\mathrm{c} 2$ & $\mathrm{~d} 1$ & $\mathrm{~d} 2$ & $\mathrm{e} 1$ & $\mathrm{e} 2$ \\
\hline $\mathrm{a} 1$ & 2.6326 & 3.6857 & 2.5311 & 3.1887 & 3.6032 \\
$\mathrm{a} 2$ & 2.2844 & 3.3462 & 3.8283 & 3.2785 & 2.0251 \\
$\mathrm{~b} 1$ & 2.7606 & 2.1605 & 3.2793 & 3.5502 & 2.3544 \\
$\mathrm{~b} 2$ & 2.6707 & 2.4313 & 3.0094 & 3.7982 & 2.8711 \\
$\mathrm{c} 1$ & 3.0682 & 3.8518 & 3.0971 & 3.7795 & 3.2188 \\
$\mathrm{c} 2$ & 0 & 2.695 & 2.8008 & 2.019 & 3.5074 \\
$\mathrm{~d} 1$ & 3.8391 & 0 & 2.2411 & 3.4922 & 3.0023 \\
d2 & 2.7629 & 2.7243 & 0 & 2.7205 & 3.4339 \\
$\mathrm{e} 1$ & 3.316 & 3.453 & 2.0418 & 0 & 3.187 \\
$\mathrm{e} 2$ & 3.213 & 3.4492 & 3.7852 & 3.7935 & 0 \\
\hline
\end{tabular}

Step 2: Get a direct score matrix. The initial score matrix $\boldsymbol{A}$ is normalized so that the direct impact matrix $\boldsymbol{X}$ meets the sum of 1 with at least one row or one column. By using Eq. (1) and (2).

$$
\begin{aligned}
& s=\min \left\{1 / \max _{i} \sum_{j}^{n} z_{i j}, 1 / \max _{j} \sum_{i=1}^{n} z_{i j}\right\} \\
& X=s Z
\end{aligned}
$$

Step 3: Obtain the total influence matrix $\boldsymbol{T}$ using Eq.(3).

$$
T=\mathrm{X}+\mathrm{X}^{2}+X^{3}+\ldots+X^{n}=X(I-X)^{-1}
$$

Step 4: Construct the INRM. Each row and column of the total influence matrix $T=\left[\mathrm{t}_{\mathrm{ij}}\right]$ is totaled to obtain the sum of all row and column vectors, as indicated in Eqs. (4)-(5). The influence between dimensions or by influence degree is showed in Table 3:

$$
\begin{aligned}
& \left.k=\left[k_{i}\right]_{n \times 1}=\sum_{j=1}^{n} t_{i j}\right]_{n \times 1}=\left(k_{1}, \cdots k_{i} \cdots, k_{n}\right) \\
& \left.d=\left[d_{j}\right]_{1 \times n}=\sum_{i=1}^{n} t_{i j}\right]_{1 \times n}=\left(d_{1}, \cdots d_{i} \cdots, d_{n}\right)
\end{aligned}
$$

Among them, $\boldsymbol{k}_{\boldsymbol{i}}$ represents the total influence value of influencing factor $\boldsymbol{i}$ on other factors; $\boldsymbol{d}_{\boldsymbol{i}}$ represents the total influence value of influencing factor $\boldsymbol{i}$ on other factors; $\boldsymbol{k}_{\boldsymbol{i}}+\boldsymbol{d}_{\boldsymbol{i}}$ represents the total influence degree value of

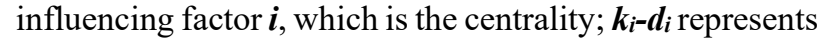
the net influence degree value of influencing factor $\boldsymbol{i}$, which is the causation degree.

Table 3 Influence between dimensions or by influence degree

\begin{tabular}{ccccc}
\hline \multirow{2}{*}{ Dimensions } & $\boldsymbol{k} \boldsymbol{i}$ & $\boldsymbol{d i}$ & $\boldsymbol{k i}+\boldsymbol{d i}$ & $\boldsymbol{k i}-\boldsymbol{d i}$ \\
\hline A & 3.9635 & 4.0529 & 8.0164 & -0.0895 \\
B & 3.8063 & 3.9783 & 7.7846 & -0.172 \\
C & 4.2273 & 3.9395 & 8.1668 & 0.2878 \\
D & 4.1193 & 4.1215 & 8.2407 & -0.0022 \\
E & 4.2635 & 4.2877 & 8.5512 & -0.0242 \\
\hline
\end{tabular}

\subsection{Based on the method of DANP to measure the weight of each dimension and the index}

DANP method is an ANP method proposed by Professor Zeng on the basis of DEMATEL. The total influence matrix of DEMATEL is taken as the unweighted super matrix of ANP, which eliminates the steps of questionnaire 
and can be used to calculate the weight of indicators.

Step 1: Normalize the matrix $\boldsymbol{T}_{c}$ and $\boldsymbol{T}_{\boldsymbol{d}}$ to obtain matrix $\boldsymbol{T}_{c}{ }^{a}$ and matrix $\boldsymbol{T}_{d}{ }^{a}$. The total influence matrix $\boldsymbol{T}_{\boldsymbol{c}}$ in a criterion level and $\boldsymbol{T}_{\boldsymbol{d}}$ in a dimension level are obtained from the previous section. Notably, the value of $\boldsymbol{T}_{\boldsymbol{d}}$ is the mean of the values in the corresponding dimension $\boldsymbol{T}_{\boldsymbol{c}}$. The normalization process of matrix $\boldsymbol{T}_{\boldsymbol{c}}$ is outlined in Eqs. (6)(11)

$$
\begin{aligned}
& d_{i}=\sum_{j=1}^{n} t_{D}^{i j}, i=1,2, \cdots n \\
& t_{D}^{\alpha^{i j}}=t_{D}^{i j} / d_{i}, i=1,2, \cdots, n \\
& T_{D}=\left[\begin{array}{ccccc}
t_{D}^{11} & \cdots & t_{D}^{1 j} & \cdots & t_{D}^{1 m} \\
\vdots & & \vdots & & \vdots \\
t_{D}^{i 1} & \cdots & t_{D}^{i j} & \cdots & t_{D}^{i m} \\
\vdots & & \vdots & & \vdots \\
t_{D}^{m 1} & \cdots & t_{D}^{m j} & \cdots & t_{D}^{m m}
\end{array}\right]_{m \times m} \\
& T_{D}^{\alpha}=\left[\begin{array}{ccccc}
t_{D}^{11} / d_{1} & \cdots & t_{D}^{1 j} / d_{1} & \cdots & t_{D}^{1 m} / d_{1} \\
\vdots & & \vdots & & \vdots \\
t_{D}^{i 1} / d_{i} & \cdots & t_{D}^{i j} / d_{i} & \cdots & t_{D}^{i m} / d_{i} \\
\vdots & & \vdots & & \vdots \\
t_{D}^{m 1} / d_{m} & \cdots & t_{D}^{m j} / d_{m} & \cdots & t_{D}^{m m} / d_{m}
\end{array}\right] \\
& =\left[\begin{array}{ccccc}
t_{D}^{\alpha 11} & \cdots & t_{D}^{\alpha 1 j} & \cdots & t_{D}^{\alpha 1 m} \\
\vdots & & \vdots & & \vdots \\
t_{D}^{\alpha i 1} & \cdots & t_{D}^{\alpha i j} & \cdots & t_{D}^{\alpha i m} \\
\vdots & & \vdots & & \vdots \\
t_{D}^{\alpha m 1} & \cdots & t_{D}^{\alpha m j} & \cdots & t_{D}^{\alpha m m}
\end{array}\right]_{m \times m} \\
& \begin{array}{ll}
D_{1} & c_{11}
\end{array} \\
& c_{12}
\end{aligned}
$$

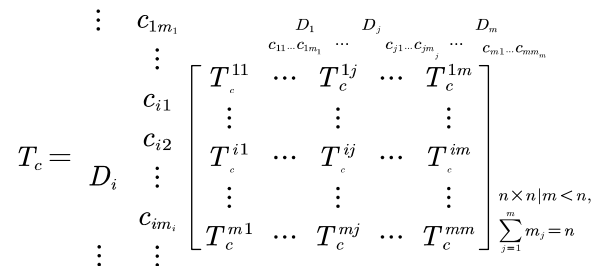

$$
\begin{aligned}
& c_{m 1} \\
& c_{m 2} \\
& D_{m} c_{m m_{m}} \\
& \begin{array}{ll}
D_{1} & c_{11}
\end{array}
\end{aligned}
$$

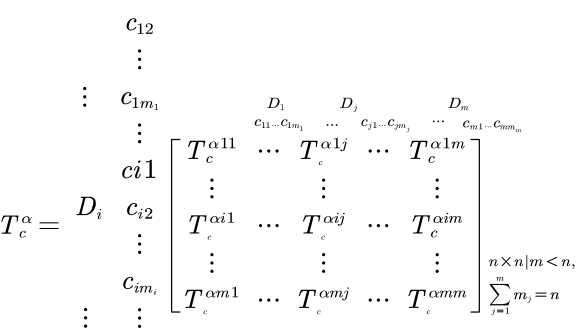

$$
\begin{aligned}
& c_{m 1} \\
& c_{m 2} \\
& D_{m} c_{m m_{m}}
\end{aligned}
$$

\section{Result}

According to the influence relationship network diagram, As shown in Figure 1. Professional knowledge (C) has the greatest impact on the other 4 dimensions, which in turn affect self-management ability (D), physical quality (E), personal traits (A) and marketing 
management ability (B). This shows that wine sales, professional knowledge is essential, sales managers need to be familiar with the vintage of wine production, variety, origin and dietary collocation, in order to better recommend to customers. Self-management ability (D) also had a significant impact on physical fitness (E), personal traits (A) and marketing management ability (B). This is because marketing activities are constantly updated, requiring sales managers to innovate ways and ideas to attract customers to buy. Physical fitness (E) also has an impact on personal traits (A) and marketing management ability (B), because sales itself requires strong energy, and strong physical fitness can better adapt to the sales environment. Personal traits (A) and marketing management ability (B) are greatly affected by other dimensions, because in the wine marketing market, it is mainly affected by wine brand and price factors, and too little consideration is given to personal factors and marketing ability.

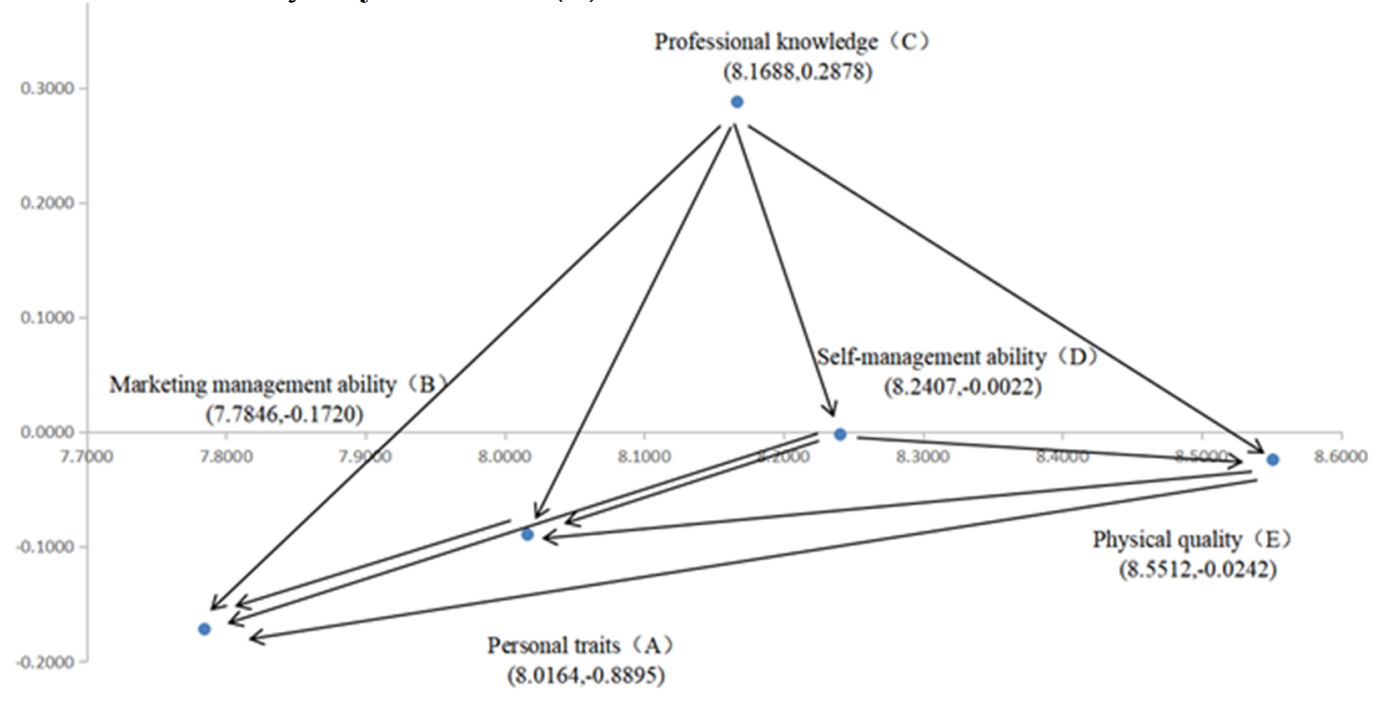

Fig.1 Dimensions affect the relational network graph

According to the results in Table 5, the weight ratios of personal traits (A), marketing management ability (B), professional knowledge (C), self-management ability (D) and physical quality (E) are $19.88 \%, 19.51 \%$, $19.35 \%, 20.22 \%$ and $21.04 \%$, respectively. According to the results, it can be seen that the proportion difference of these 5 dimensions is not very big, and the distribution is relatively uniform. Among them, self-management ability and physical quality accounted for a higher proportion. Because the sales manager plans and implements different activities, it is necessary to carry out continuous innovation, which requires a high learning and thinking ability. The design, inspection and implementation of the planning scheme, as well as the discussion and communication with customers, all need to be carried out continuously. There are also high requirements for the physical quality of sales managers. Secondly, they also need to have strong personal characteristics and marketing management ability. A good sales manager needs to have strong personality charm, so that he can lead the team to complete the goals and tasks as expected. He also needs to have sufficient sales skills and have an understanding of profits, rebates and transportation methods. At the same time, as a wine sales manager also need to have a high level of professional knowledge, and can communicate with customers, professional level.
Table 5 Weighting within the wine sales manager dimension and global weight

\begin{tabular}{ccc}
\hline Dimensions/Factors & $\begin{array}{c}\text { Weight } \\
\text { within } \\
\text { dimension }\end{array}$ & $\begin{array}{c}\text { Global } \\
\text { weight }\end{array}$ \\
\hline Personal traits (A) & 0.1988 & \\
Team spirit (a1) & 0.4824 & 0.0959 \\
Adaptive (a2) & 0.5176 & 0.1029 \\
Marketing management ability (B) & 0.1951 & \\
Policy sensitivity (b1) & 0.4854 & 0.0947 \\
Customer Service Awareness (b2) & 0.5146 & 0.1004 \\
Professional knowledge (C) & 0.1935 & \\
Wine knowledge (c1) & 0.4873 & 0.0943 \\
Experience (c2) & 0.5127 & 0.0992 \\
Self-management ability (D) & 0.2022 & \\
Learning ability (d1) & 0.5109 & 0.1033 \\
\hline
\end{tabular}

\section{Conclusions and remarks}

This paper explores the systematic identification and analysis of key factors that influence wine sales managers and calculates the performance weights of these factors. Managers in the wine industry can use these results to provide scientific decision-making basis and recommendations for the selection, performance 
evaluation management, training and professional development of wine sales managers. The conclusions and contributions of this study are summarized as follows:

(1) Determine the key characteristics of wine sales manager and build a model.

(2) Discusses the wine sales manager competency of each dimension and the interaction relationship between indicators.

(3) Each dimension and index weight of competency are obtained.

However, this study also has some limitations, which should be recognized and valued. First of all, the number of experts should be more appropriate to ensure that expert advice can fully cover all aspects of the wine industry. Secondly, it should be analyzed by actual cases. Finally, the wine industry is an emerging industry, and future research needs to expand the research scope to make the data more accurate.

\section{References}

1. Peng K H, Tzeng G H.(2017) Exploring heritage tourism performance improvement for making sustainable development strategies using the hybridmodified MADM model. Current Issues in Tourism, (3): 1-27.

2. Nordhaus O. (1998) Competency specificities in organizations. International Studies of Management \& organization,28(1):8-29 .

3. Li W., Yao H., Chen K., Ju Y., (2021) Effect of foliar application of fulvic acid antitampering on sugar accumulation, phenolic profiles and aroma qualities of Cabernet Sauvignon and Riesling grapes and wines. Food Chemistry,2,351.

4. Dong W., Li B., Wei J., Tian N., Liang W., Zhang J. (2021) Environmentally friendly, durable and transparent anti-fouling coatings applicable onto various substrates. Journal of Colloid And Interface Science,591.

5. Pereira Giuliano E., Padhi Emily M.T.(2021) Impact of grapevine red blotch disease on primary and secondary metabolites in 'Cabernet Sauvignon' grape tissues. Food Chemistry,2021,342.

6. Prata Joana C., Paço Ana. (2021) Comment on recent article "Identification of microplastics in white wines capped with polyethylene stoppers using micro-Raman spectroscopy", published in Food Chemistry (2020). Food Chemistry,342.

7. Fu Hui-Jun, Chen Zi-Jian. (2021) Development of a sensitive non-competitive immunoassay via immunocomplex binding peptide for the determination of ethyl carbamate in wine samples. Journal of Hazardous Materials,406. 